\title{
The performance research of a solar heating system in Tangshan
}

\author{
Bin Yang ${ }^{1, a^{*}}$, Yashuai Yang ${ }^{2, b}$ and Degong Zuo ${ }^{3, c}$ \\ ${ }^{1}$ School of Energy and Environment Engineering, Hebei University of Technology, China \\ ${ }^{2}$ School of Energy and Environment Engineering, Hebei University of Technology, China \\ ${ }^{3}$ School of Energy and Environment Engineering, Hebei University of Technology, China \\ a yangbin0720@126.com, b953359943@qq.com, ${ }^{c} 1123550491 @ q q . c o m$
}

Keywords: vacuum tube collector. the solar energy. efficiency.

Abstract. In this paper, we study the heating building for Tangshan one residential and the project chooses solar vacuum tube collector. The system is running around the water temperature, water flow and solar radiation test record. We calculated the instantaneous collector efficiency, system instantaneous efficiency and daily average efficiency of the system, and the instantaneous collector efficiency and system change of instantaneous efficiency have been make a line chart, the system of the average daily efficiency through calculation shows an average $\mathrm{f}$ rom $30 \%$ to $50 \%$, and evaluate all the results are given.

\section{Introduction}

Energy as a kind of strategic natural resources promotes the economic and social progress and it is a kind of important material base, which can safeguard China's economic sustainable development ${ }^{[1]}$.There is a growing international hot spot that is in the solar energy technology development and application of solar energy. On the solar energy heat utilization, hot water system is widely used solar energy, its heat utilization by the year 2030 is expected to reach 35 Mtoe. Many of the organisation for economic co-operation and development countries use 15\% 20\% of energy consumption for heating water, and until 2030, solar will be used for hot water system and occupy a larger share in the consumption of production ${ }^{[2]}$.

Solar heating is very prospect and heating scheme of efficiency is very high, it not only energy saving but also can achieve ideal effect. Solar heating system consists of the solar collector, water tank, piping, control system and other auxiliary materials ${ }^{[3]}$. Its working principle is to spread the solar energy through the collector is converted into heat, and the heat is used for heating hot water, hot water is stored in the hot water storage box. The hot water to the terminal device can provide heat for buildings ${ }^{[4]}$.

\section{The working principle of vacuum tube type collector}

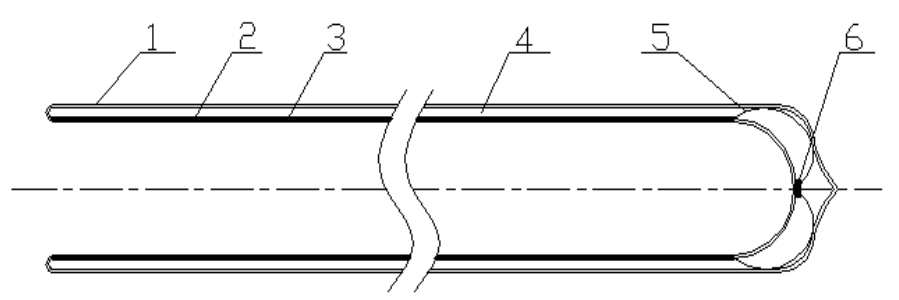

1-Outside the glass tube 2-Inside the glass tube 3 - Selective absorbing coating 4-Vacuum sandwich 5- Spring support 6- Getter device

Fig1 All-glass vacuum solar thermal collectors structure and components

The inner tube as the flow of heating medium such as water pipes; By using vacuum deposition, electrochemical processing technology, such as copper oxide solar selective absorption coating evenly, the pipe outside surface, to absorb solar radiation. Between the inner and outer glass tube into the vacuum degree is a vacuum sandwich of $0.05 \mathrm{~Pa}$, and it can reduce the heat convection and heat 
conduction of heat loss caused; All single-ended tube opening, end tube inside and outside is the ring sealing, and the inner tube hemispherical round head, the other end is sealed pieces will round head supporting the interior of the outer tube, so that they can absorb radiation to raise the temperature, and it can be in the free end of the round head to form a thermal expansion and makes the work the thermal stress is buffered on vacuum tube openings ${ }^{[5]}$.

\section{Project summary}

The system building in a village of Tangshan abundant south area is a two-bedroom bungalow, whose construction area is $70 \mathrm{~m}^{2}$ and its exterior wall insulation is made by polystyrene, firmware, plastering mortar, mesh cloth, exterior wall tiles. The exterior wall thickness is $370 \mathrm{~mm}$ and heat preservation performance is good. In addition, due to housing for the flat roof, there is plenty of space can be placed required water tank, collector, pipe fittings and other parts of the system. The building structure is relatively simple, and the use of floor heating adopted ordinary plate type tube, and the space is around $200 \mathrm{~mm}$. It is in line with the general standard.

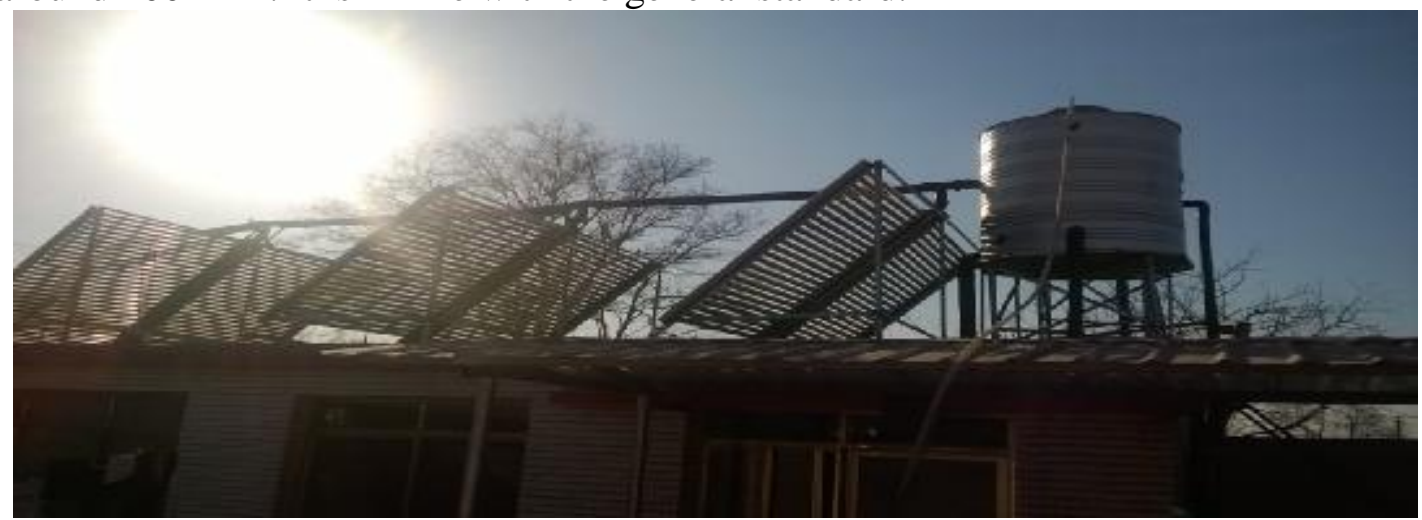

Fig2 Tangshan systems engineering field

This experiment data records using the agilent temperature recorder to record temperature, and solar radiation uses solar power meter to record. Due to the temperature and solar radiation values change over time, so the data was be recorded hourly.

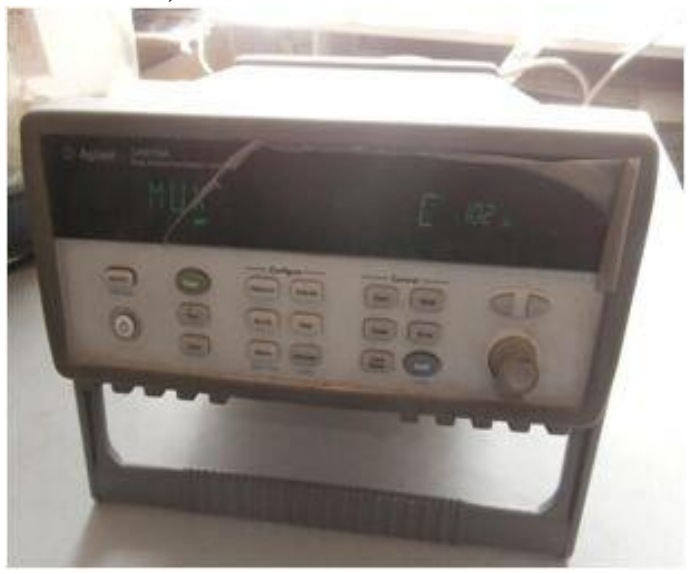

Fig3 Agilent temperature recorder

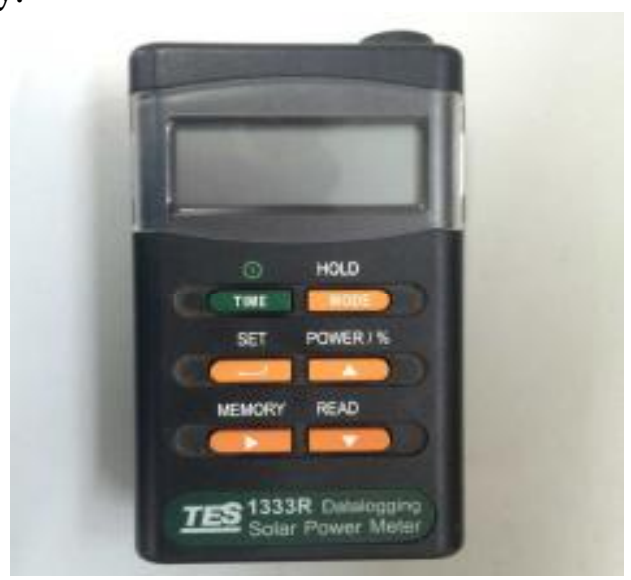

Fig4 Solar power meter

\section{Analysis of experimental results}

Instantaneous efficiency. The instantaneous efficiency is the ratio of the heat obtained from the collector and the amount of solar radiation accepted from the surface of the collector. The instantaneous efficiency is calculated as follows:

$$
\eta=\frac{M C_{P}\left(t_{i+1}-t_{i}\right)}{A\left(H_{i+1}-H_{i}\right)}
$$


Where: $\eta$-Instantaneous efficiency; $M$ - Capacity of water tank, $\mathrm{kg} ; C_{p}$ - Heat capacity of water, $\mathrm{J} /(\mathrm{kg} \cdot \mathrm{K}) ; t$ - water temperature, ${ }^{\circ} \mathrm{C} ; A$-Collector lighting area, $\mathrm{m}^{2} ; H$ - the instantaneous solar radiation, $\mathrm{J} / \mathrm{m}^{2} ; i$-Initial state; $i+1$-Final state.

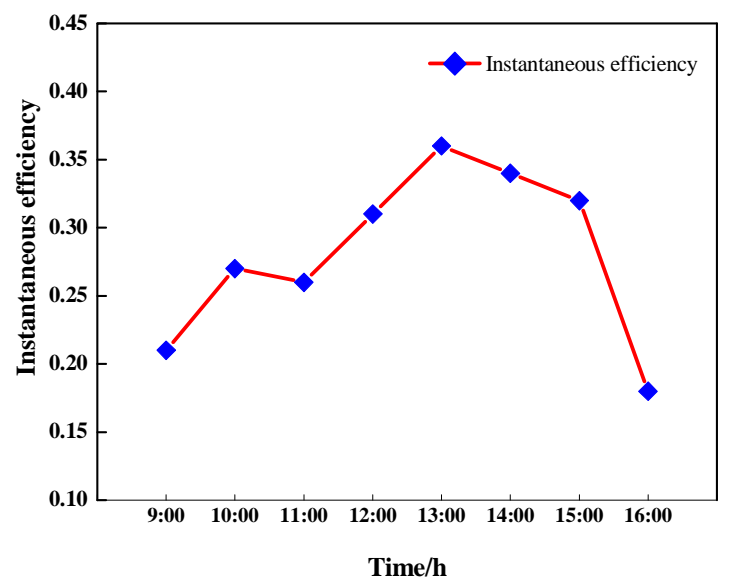

Fig5 Instantaneous efficiency in March 19th

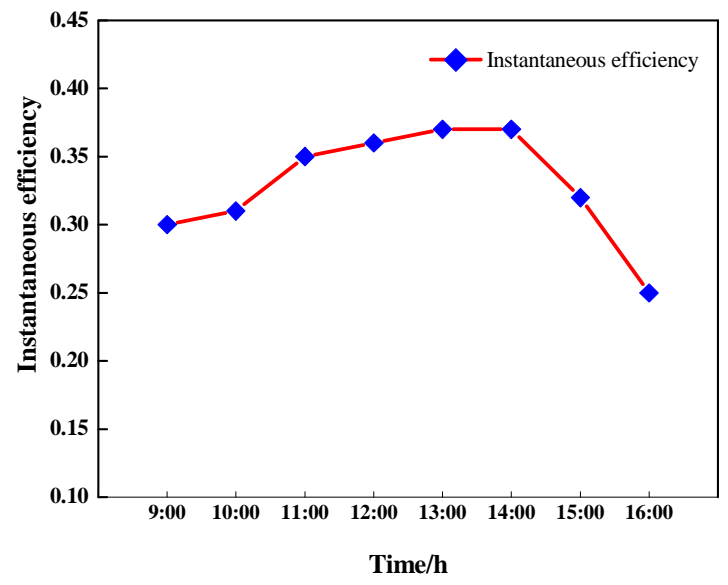

Fig6 Instantaneous efficiency in March 20th

This experiment data is too many. For example, at 19 March 9 to 16 points, It can be seen from the figure 5 that in a period of time with the sun radiation, the collector instantaneous efficiency gradually rise. As the two pumps in the system is running, so it will not have a change in the flow system. we can see the stage while the solar radiation is the strongest at noon, but the instantaneous collector efficiency is not the highest, and the efficiency at 13:00 is one of the most value. This is because at noon while the solar radiation is big, but it is not the highest collector import and export temperature difference $\left(7.9^{\circ} \mathrm{C}\right)$, and the temperature difference reaches the highest around 13:00 $\left(10^{\circ} \mathrm{C}\right)$. Compared to high noon, the radiation is weak so that they can get a higher instantaneous efficiency. This is the result because of two factors that are useful heat accumulation collected by collectors and solar radiation decreased.

Let us use the situation of March 20 as an example to verify the above conclusion. We can see from the figure 6 that while the instantaneous efficiency also shows ascendant trend, but the rising slope is not bigger than the day before. From the data analysis, we can get that the import and the export temperature difference of the collector change smaller, and it is relatively stable. The temperature difference rise obviously only between 10:00 to 11:00, and it caused the instantaneous efficiency increaseing. It is basically in line with the efficiency of the day before.

Through data analysis, we can see that the instantaneous efficiency of vacuum tube collector in a period of time with solar radiation of the instantaneous efficiency is rising gradually, which have a small fluctuations, at noon in the afternoon around 2 o 'clock efficiency value can reach high about $37 \%$ in a day.

The daily average efficiency. The average daily efficiency is a key parameter to describe performance of collectors, and it is one of the important indicators to reflect the solar-thermal conversion ability. The daily average efficiency is the ratio of the heat obtained from the collector and the amount of solar radiation accepted from the surface of the collector in the day. The daily average efficiency is calculated as follows:

$$
\eta_{d}=\frac{C_{P} M\left(t_{e}-t_{s}\right)}{A H}
$$


Where: $\eta_{d}$-Average daily efficiency; $C_{P}$ - Heat capacity of water, $J /(k g \cdot K) ; M-$ Capacity of water tank, $\mathrm{kg} ;{ }^{t}$ - Initial water temperature, ${ }^{\circ} \mathrm{C} ;{ }^{t}{ }^{t}-$ Final water temperature, ${ }^{\circ} \mathrm{C} ; H$ - the total solar radiation, $J / \mathrm{m}^{2} ; A-$ Collector lighting area,m2.

The average daily efficiency of seven days are shown in table 2.

Table 1 The average daily efficiency of seven days

\begin{tabular}{|c|c|c|c|c|}
\hline Date & $\begin{array}{c}\text { Initial water } \\
\text { temperature }{ }^{\circ} \mathrm{C}\end{array}$ & $\begin{array}{c}\text { Final water } \\
\text { temperature }{ }^{\circ} \mathrm{C}\end{array}$ & Radiation (MJ ) & $\begin{array}{c}\text { Average daily } \\
\text { efficiency }\end{array}$ \\
\hline 2015.03 .18 & 24.425 & 49.299 & 22295.83 & 0.33 \\
\hline 2015.03 .19 & 20.514 & 42.546 & 23251.44 & 0.28 \\
\hline 2015.03 .20 & 28.945 & 78.194 & 27575.04 & 0.52 \\
\hline 2015.03 .21 & 43.479 & 74.948 & 25081.11 & 0.37 \\
\hline 2015.03 .22 & 45.634 & 78.858 & 19387.58 & 0.50 \\
\hline 2015.03 .23 & 41.337 & 75.850 & 19873.32 & 0.51 \\
\hline 2015.03 .24 & 39.812 & 74.704 & 22569.03 & 0.45 \\
\hline
\end{tabular}

From the table we can see that the average daily efficiency of vacuum tube of the average daily efficiency mostly transform between 30\% 50\% in this several days, and it is not high. Mainly due to the system free run of the day, collector cannot follow the sun shifting azimuth so that make collector's optical damage larger; Moreover, this experiment is the actual project, there are many flaws. The volume of the tank is so large that the heat wasted. Piping designing unreasonably causes uneven pressure and the temperature changes of the water tank is not accuracy.

Tank temperature analysis. All the heat is from the solar vacuum tube collector of the heating system, and the auxiliary heat source is not open. The capacity of Heat storage water tank is 2 tons, and high of that are $1.8 \mathrm{~m}$ and $1.2 \mathrm{~m}$ in diameter. The tank temperature probe was installed two positions to analysis the change of temperature in the water tank.

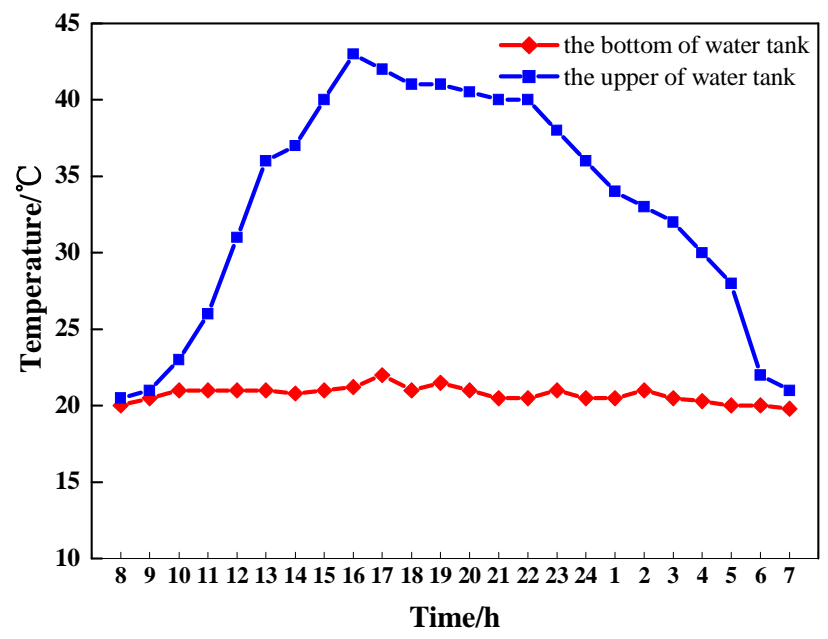

Fig7 The temperature changes of water

Figure 6 is on March 19, tank temperature changes. The weather is sunny, the valve opens at the bottom of the tank. Seen from the figure 8 to 16 points cistern upper temperature rise gradually, and the temperature gradually reduced to consistent with the tank bottom temperature. This is because 
solar radiation is sufficient in 8 to $16 \mathrm{PM}$ period, and the water in the tank can get enough heat to increase the temperature; At 16 point, the solar radiation is weaker, so the heat change between upper and lower to make the water temperature is lower, and the rate of decrease is much higher than the valve closing. It is also the result that the heat within the tank used for floor heating tube for room heating.

From the analysis, we can get that the system requires the appropriate volume, water tank volume is too big that will cause stratification in the water of the tank, the lower the low temperature water is unnecessary heat exchange with the high temperature of the upper water, and heat loss will be occur in the water tank, it also increase the initial investment; Heat capacity is too small, that cannot be fully utilized. It cause the collector outlet temperature is too high and collection efficiency will be reduced.

\section{Conclusion}

(1) The overall trend of the change of the average instantaneous efficiency of vacuum tube collector is continuous to increase. Probably around 3 o 'clock in the afternoon, it can reach the maximum. In 9 am to $3 \mathrm{PM}$ this time, the instantaneous efficiency variation is not large, the instantaneous efficiency is relatively stable.

(2) The average daily efficiency of vacuum tube collector in about $30 \%$ to $50 \%$. The measured indoor temperature can reach 18 and relatively stable, but the system of the test is on March, and environment temperature is higher. As if considering heating engineering use in the winter, it can't meet the demand and still need auxiliary heat source to maintain room temperature.

(3) Stratification of the Water tank is more serious, and the reason is the volume of the tank is too large. The heat from collectors into the tank cannot be fully utilized, and system piping set is not reasonable. It causes circulation system, and finally it can affect the temperature of the water tank water level.

\section{Acknowledgement}

This work was financially supported by National Major Project of Scientific and Technical Supporting Programs of China during the 12th Five-year Plan Period (Grant No. 2012BAJ06B04), Tianjin Education Commission Scientific Research project(Grant No. 20140418), the project of 2015 Tianjin Technological Innovation to guide specially outstanding Science and Technology Correspondent and the Science and Technology Research Youth Fund project of universities in Hebei province(Grant No. 2015028).

\section{References}

[1] Chunying Zhou, Hongqiang Yang. China's industrial energy efficiency industry differences and energy saving potential, J. Journal of shanxi university of finance and economics, 2013,09:84-93.

[2]Hao Meng, Yingjian Chen. The present situation of technique of solar energy utilization in China and its countermeasures, J. Science and technology of China BBS,2009,05:96-101.

[3] Chengxian Luo. The popularity of solar power and prospect, J. The Chinese and foreign energy,2010,11:33-39.

[4] Zhentao Luo, Zhichen Huo. The solar water heater industry development present situation in our country. The solar energy,2003 (1)

[5] Junliang Zhu, Based on the research of fire wall system of heating of the fire resistance of rural, D. Dalian university of technology,2010 